\title{
Regioselective decarboxylative addition of malonic acid and its mono(thio)esters to 4-trifluoromethylpyrimidin-2(1H)-ones
}

\author{
Sergii V. Melnykov ${ }^{1}$, Andrii S. Pataman², Yurii V. Dmytriv²,3, Svitlana V. Shishkina ${ }^{4,5}$, \\ Mykhailo V. Vovk ${ }^{1}$ and Volodymyr A. Sukach ${ }^{* 1}$
}

Open Access

\author{
Full Research Paper \\ Address: \\ ${ }^{1}$ Institute of Organic Chemistry, National Academy of Sciences of \\ Ukraine, 5 Murmanska str., Kyiv 02660, Ukraine, ${ }^{2}$ Enamine LTD, 78 \\ Chervonotkats'ka str., Kyiv 02094, Ukraine, ${ }^{3}$ National Technical \\ University of Ukraine "Igor Sikorsky Kyiv Polytechnic Institute", 37 \\ Peremohy ave., Kyiv 03056, Ukraine, ${ }^{4}$ STC "Institute for Single \\ Crystals", National Academy of Sciences of Ukraine, 60 Nauky ave., \\ Kharkiv 61001, Ukraine and 5 Department of Inorganic Chemisrtry, \\ V.M. Karasin Kharkiv National University, 4 Svobody sq, Kharkiv \\ 61122, Ukraine \\ Email: \\ Volodymyr A. Sukach* - vsukach@gmail.com \\ * Corresponding author \\ Keywords: \\ ketimines; malonic acid; Michael- and Mannich-type decarboxylative \\ addition; pyrimidin-2(1H)-ones; regioselectivity; trifluoromethyl group
}

\author{
Beilstein J. Org. Chem. 2017, 13, 2617-2625. \\ doi:10.3762/bjoc. 13.259
}

Received: 03 August 2017

Accepted: 20 November 2017

Published: 07 December 2017

This article is part of the Thematic Series "Organo-fluorine chemistry IV".

Guest Editor: D. O'Hagan

(C) 2017 Melnykov et al.; licensee Beilstein-Institut.

License and terms: see end of document.

\begin{abstract}
Background: Due to the high reactivity towards various C-nucleophiles, trifluoromethylketimines are known to be useful reagents for the synthesis of $\alpha$-trifluoromethylated amine derivatives. However, decarboxylative reactions with malonic acid and its mono(thio)esters have been poorly investigated so far despite the potential to become a convenient route to $\beta$-trifluoromethyl- $\beta$ amino acid derivatives and to their partially saturated heterocyclic analogues.
\end{abstract}

Results: In this paper we show that 4-trifluoromethylpyrimidin-2(1H)-ones, unique heterocyclic ketimines, react with malonic acid under organic base catalysis to regioselectively provide either Michael- or Mannich-type decarboxylative addition products depending on solvent polarity. Malonic mono(thio)esters give exclusively Michael-type products. The two regioisomeric products can be converted into saturated (2-oxohexahydropyrimidin-4-yl)acetic acid derivatives by mild hydrogenation of the endocyclic $\mathrm{C}=\mathrm{C}$ double bond in the presence of $\mathrm{Pd} / \mathrm{C}$ as catalyst. The cis-stereoisomers selectively formed upon reduction of the Michael-type products were structurally determined by X-ray diffraction. As a result of this study, a number of novel acetic acid derivatives containing trifluoromethylated, partially or fully saturated 2-oxopyrimidine cores were prepared and characterized as promising building blocks.

Conclusions: Regio- and stereoselective protocols have been developed for the synthesis of novel isomeric 4(6)-trifluoromethylated 1,2,3,4-tetrahydro- and perhydro-(2-oxopyrimidin-4-yl)acetic acid derivatives. 


\section{Introduction}

Organofluorine compounds now play an essential role in the development of new materials for solar cells [1-3], radiotracers for PET imaging [4], agrochemicals [5,6], sensitive chemical probes for ${ }^{19} \mathrm{~F}$ nuclear magnetic resonance investigation of biological experiments $[7,8]$, and are most widely used in the modern drug discovery and development area $[9,10]$. As a result of intensive research efforts over the last decades, efficient fluorination and fluoroalkylation methods have emerged to prepare previously challenging molecules decorated with fluorine atoms or fluorinated groups which make them practically useful [11-14]. A building-block approach remains an alternative strategy to the synthesis of fluorine-containing compounds. This complementary method takes advantage of specific reagents featuring original fluorinated motives and/or functional groups which affords more complex derivatives via conventional functionalization or (hetero)cyclization [15-17]. Among these reagents, trifluoromethylketimines have drawn much research interest in recent years as key starting materials for the synthesis of trifluoromethyl-substituted amines [18,19], $\alpha$-amino acids [20-23] as well as nitrogen-containing heterocyclic compounds [24-29]. It should be noted that the presence of a strong electron-withdrawing trifluoromethyl group is responsible for the sufficient reactivity of the electrophilic ketimine function with various carbon nucleophiles in these reactions.

Recently, the decarboxylative addition of malonic acid mono(thio)esters to aldehydes and imines has become an increasingly popular synthetic strategy [28,30-36]. However, the utility of trifluoromethylketimines as electrophilic substrates in this reaction remains underinvestigated. The only published work from the group of Ma described the development of a chiral thiourea-catalyzed enantioselective decarboxylative Mannich reaction of malonic acid monoesters with 4-trifluoromethylquinazolin-2(1H)-ones as heterocyclic trifluoromethylketimine substrates for the preparation of enantioenriched 3,4-dihydroquinazolin-2(1H)-ones and the anti-HIV drug DPC 083 [28]. No examples of any ketimines reacting directly with malonic acid have been reported so far.

Here we present the results of the decarboxylative addition of malonic acid, malonic monoester $\mathbf{1 a}$ and thioester $\mathbf{1 b}$ to 4 -trifluoromethylpyrimidin-2(1H)-ones 2 (Figure 1). These compounds are unique heterocyclic conjugated trifluoromethylketimines with two competing electrophilic centers which can enable either Michael- or Mannich-type nucleophilic additions. As found in our previous studies, organocatalytic addition of acetone [37], nitromethane [38] and trimethylsilyl cyanide [39] in most cases can be performed regioselectively after optimization of the reaction conditions (temperature, solvent, time and catalyst nature). In general, under kinetic reaction control, the Michael-type 1,4-adducts are the predominant products while under thermodynamic control, the regioisomeric Mannich-type 1,2-adducts are more likely to be formed. These observations allowed us to develop selective methods for the synthesis of functionalized partially saturated 4-trifluoromethyl-substituted pyrimidin-2 $(1 H)$-ones, in particular, 4,5-dihydroorotic acid analogues 3 [39]. Here we report the preparation of acid 3 homologues (with a methylene linker between the carboxylic group and the pyrimidine ring) and their isomers resulting from two alternative regioselective pathways for the decarboxylative nucleophilic addition of malonic acid and its mono(thio)esters.

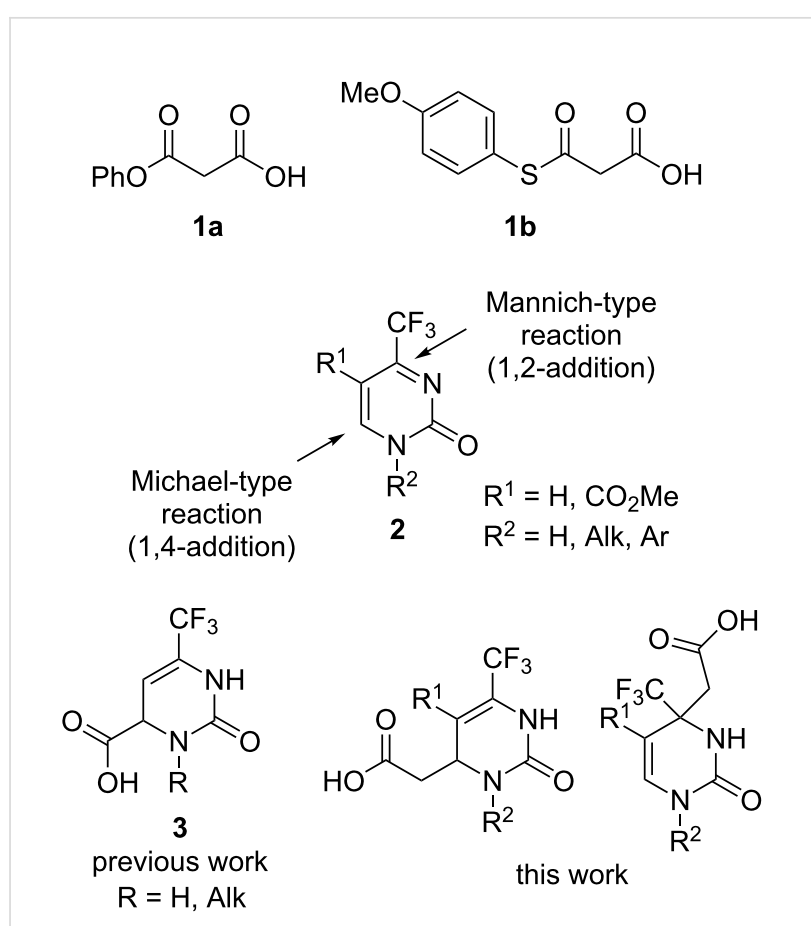

Figure 1: Summary of the present study.

\section{Results and Discussion}

We first screened organic base catalysts, solvents and temperature in the decarboxylative addition of malonic acid (nucleophilic component) to 1-methyl-4-trifluoromethylpyrimidin2(1H)-one (2a, the simplest model substrate) aiming to find the optimal organocatalytic reaction conditions (Table 1). In the preliminary experiments, it was established that the reaction was quite slow; heating and a 5-fold excess of malonic acid were required to reach a reasonable conversion. Additionally, it was found that a stoichiometric amount of a model catalyst, triethylamine (TEA), was necessary for the reaction to proceed efficiently. Thus, heating the reaction mixture in toluene at $80{ }^{\circ} \mathrm{C}$ for $18 \mathrm{~h}$ in the presence of 1 equivalent of TEA resulted 
Table 1: Screening of the reaction conditions for organic base-catalyzed malonic acid addition to 1-methyl-4-trifluoromethylpyrimidin-2(1H)-one $(2 \mathrm{a})$.

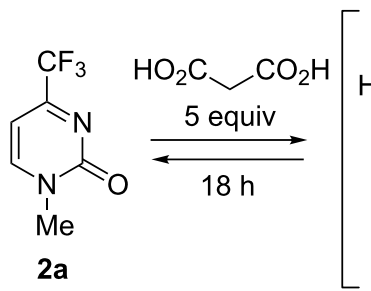<smiles>[B]N1C=CC(C(=O)O)(C(C(=O)O)C(F)(F)F)NC1=O</smiles><smiles>CN1C(=O)NC(C(F)(F)F)=CC1C(C(=O)O)C(=O)O</smiles><smiles>CN1C=CC(CC(=O)O)(C(F)(F)F)NC1=O</smiles><smiles>CN1C(=O)NC(C(F)(F)F)=CC1CC(=O)O</smiles>

\begin{tabular}{|c|c|c|c|c|c|c|}
\hline entry & base (1 equiv) & solvent & temp. $\left({ }^{\circ} \mathrm{C}\right)$ & conv. $(\%)$ & 4a:5a ratio $(\%)$ & product (isolated yield, \%) \\
\hline 1 & TEA & toluene & 80 & 84 & $92: 8$ & $4 a(68)$ \\
\hline 2 & TEA & THF & 65 & 97 & $13: 87$ & $5 a(63)$ \\
\hline 3 & TEA & DMSO & 80 & 94 & $1: 99$ & $5 \mathbf{a}(85)$ \\
\hline 4 & TEA & $\mathrm{MeOH}$ & 63 & 46 & $21: 79$ & - \\
\hline 5 & DIEA & toluene & 80 & 83 & $88: 12$ & $4 a(66)$ \\
\hline 6 & DBU & toluene & 80 & 80 & $85: 15$ & - \\
\hline 7 & quinine & toluene & 80 & 81 & $47: 53^{a}$ & - \\
\hline 8 & & toluene & 80 & 62 & $34: 66^{a}$ & - \\
\hline
\end{tabular}

aThe two regioisomers were racemic.

in a satisfactory $84 \%$ conversion and led to the Mannich-type product, (1-methyl-2-oxo-4-trifluoromethyl-1,2,3,4-tetrahydropyrimidin-4-yl)acetic acid (4a), along with a small amount of the Michael-type regioisomer $\mathbf{5 a}$ (Table 1, entry 1 ). The reaction course and the ratio of the regioisomers formed were conveniently monitored by ${ }^{19} \mathrm{~F}$ NMR spectroscopy. Acid 4a precipitated in pure form on evaporating toluene and treating the residue with diluted hydrochloric acid. Performing the reaction in a more polar solvent such as THF drastically shifted the regioselectivity to the Michael-type adduct formation (Table 1, entry 2). Using DMSO as solvent and heating the reaction at $80{ }^{\circ} \mathrm{C}$ provided exclusively (3-methyl-2-oxo-6-trifluoromethyl1,2,3,4-tetrahydropyrimidin-4-yl)acetic acid (5a) in high isolated yield (Table 1, entry 3). Methanol proved to be an unsuitable solvent for this reaction in terms of both conversion and selectivity (Table 1, entry 4). Likewise, diisopropylethylamine (DIEA) and 1,8-diazabicyclo[5.4.0]undec-7-ene (DBU) were found to be not superior to TEA as catalysts (Table 1, entries 5 and 6). Unfortunately, quinine and the chiral quinine-derived thiourea organocatalyst QT in toluene led to a mixture of racemic products along with $19 \%$ and $38 \%$ of unreacted starting material, respectively (Table 1, entries 7 and 8 ).
As seen from the screening results, the reaction regioselectivity is easily solvent controlled. Non-polar toluene is the preferential solvent for the Mannich-type decarboxylative addition to the $\mathrm{C}=\mathrm{N}$ double bond while polar DMSO promotes the highly selective Michael-type addition to the $\mathrm{C}=\mathrm{C}$ double bond. These observations are explained by the fact that the initially formed (kinetically controlled) Michael-type dicarboxylate adduct $\mathbf{A}$ is much more stable in a low-polar than in a high-polar solvent (Table 1). In the former case, the long-living intermediate $\mathbf{A}$ is gradually converted, via the reversible first reaction step, into the energetically advantageous (thermodynamically controlled) Mannich-type adduct $\mathbf{B}$, followed by rapid irreversible decarboxylation of $\mathbf{B}$ into compound $\mathbf{4 a}$. Contrastingly, in a high-polar solvent, the intermediate $\mathbf{A}$ is so labile that it undergoes decarboxylation to product $\mathbf{5 a}$ rather than rearrangement to B. The proposed reaction mechanism is supported by the known effect of solvent polarity on the decarboxylation rate of malonic acid derivatives which was claimed to be faster in polar media [40].

To study the substrate scope of the regioselective additions of malonic acid, we introduced substituted pyrimidones $\mathbf{2} \mathbf{b}-\mathbf{m}$ in 
the reaction and performed it under optimal conditions using toluene or DMSO as solvent and TEA (1 equiv) as catalyst (Table 2). The alkyl substituent at the nitrogen atom of the substrate had no significant effect on the reaction course. In all cases, both regioisomers, $\mathbf{4 b}-\mathbf{i}$ and $\mathbf{5 b}-\mathbf{i}$, were isolated in modest to high yields (Table 2, entries 1-16). The presence of the ester functionality at position 5 of the heterocycle led to product mixtures if toluene was used as solvent so that products $\mathbf{4} \mathbf{j}-\mathbf{m}$ could not be obtained selectively and separated. In DMSO solution, the corresponding Michael-type adducts $\mathbf{5 j}-\mathbf{m}$ were smoothly formed and obtained in $75-83 \%$ isolated yields (Table 2, entries 17-20). 4-Trifluoromethylpyrimidin-2(1H)ones 2 lacking a substituent at position 1 (structures not shown) were found to be completely unreactive in the decarboxylative reaction under study.

With the aim of preparing the corresponding N1(3)-unsubstituted products $\mathbf{4 j}$ and $\mathbf{5 n}, \mathbf{0}$, we utilized N1(3)-(4-methoxybenzyl) derivatives $\mathbf{4 i}, \mathbf{5 i}, \mathbf{5 k}$ in trifluoroacetic acid (TFA); the resulting cleavage of the 4-methoxybenzyl (PMB) group afforded the target compounds in good yields (see Table 2).

Next we studied the decarboxylative addition of reagent 1a to model substrate $\mathbf{2 a}$ (Table 3 ) to compare the reactivity of malonic acid and its monophenyl ester 1a. It was proved again that the reaction proceeded sufficiently fast in toluene only in

Table 2: Regioselective decarboxylative addition of malonic acid to 4-trifluoromethylpyrimidin-2(1H)-ones $\mathbf{2 b}-\mathbf{m}$ and preparation of $N 1$ (3)-unsubstituted compounds $4 \mathrm{j}$ and $\mathbf{5 n}, \mathbf{0}$.

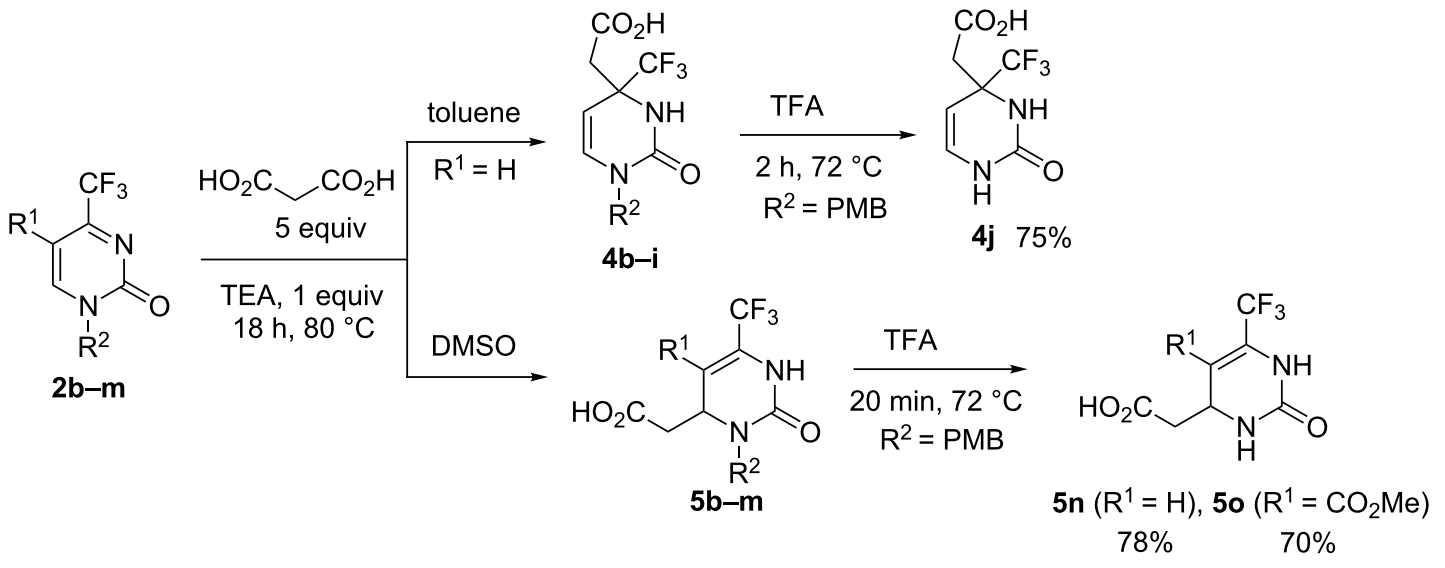

\begin{tabular}{|c|c|c|c|c|c|}
\hline entry & comp. 2 & $\mathrm{R}^{1}$ & $\mathrm{R}^{2}$ & isol. product & yield (\%) \\
\hline 1 & b & $\mathrm{H}$ & $\mathrm{Et}$ & $4 b$ & 62 \\
\hline 2 & b & $\mathrm{H}$ & Et & $5 b$ & 58 \\
\hline 3 & c & $\mathrm{H}$ & $n-\mathrm{Bu}$ & $4 c$ & 67 \\
\hline 4 & C & $\mathrm{H}$ & $n-\mathrm{Bu}$ & $5 c$ & 55 \\
\hline 5 & d & $\mathrm{H}$ & $\mathrm{Me}_{2} \mathrm{CHCH}_{2}$ & $4 d$ & 57 \\
\hline 6 & d & $\mathrm{H}$ & $\mathrm{Me}_{2} \mathrm{CHCH}_{2}$ & $5 d$ & 51 \\
\hline 7 & e & $\mathrm{H}$ & $\mathrm{MeOCH}_{2} \mathrm{CH}_{2}$ & $4 e$ & 59 \\
\hline 8 & e & $\mathrm{H}$ & $\mathrm{MeOCH}_{2} \mathrm{CH}_{2}$ & $5 e$ & 64 \\
\hline 9 & $f$ & $\mathrm{H}$ & $\mathrm{CH}_{2}=\mathrm{CHCH}_{2}$ & $4 f$ & 73 \\
\hline 10 & $\mathbf{f}$ & $\mathrm{H}$ & $\mathrm{CH}_{2}=\mathrm{CHCH}_{2}$ & $5 f$ & 82 \\
\hline 11 & $\mathbf{g}$ & $\mathrm{H}$ & $\mathrm{Bn}$ & $4 \mathrm{~g}$ & 68 \\
\hline 12 & $\mathbf{g}$ & $\mathrm{H}$ & $\mathrm{Bn}$ & $5 g$ & 89 \\
\hline 13 & $\mathbf{h}$ & $\mathrm{H}$ & $4-\mathrm{FC}_{6} \mathrm{H}_{4} \mathrm{CH}_{2}$ & $4 h$ & 60 \\
\hline 14 & $\mathbf{h}$ & $\mathrm{H}$ & $4-\mathrm{FC}_{6} \mathrm{H}_{4} \mathrm{CH}_{2}$ & $5 h$ & 80 \\
\hline 15 & $\mathbf{i}$ & $\mathrm{H}$ & 4- $\mathrm{MeOC}_{6} \mathrm{H}_{4} \mathrm{CH}_{2}$ & $4 \mathbf{i}$ & 65 \\
\hline 16 & $\mathbf{i}$ & $\mathrm{H}$ & 4- $\mathrm{MeOC}_{6} \mathrm{H}_{4} \mathrm{CH}_{2}$ & $5 i$ & 82 \\
\hline 17 & $\mathbf{j}$ & $\mathrm{CO}_{2} \mathrm{Me}$ & $4-\mathrm{FC}_{6} \mathrm{H}_{4} \mathrm{CH}_{2}$ & $5 j$ & 75 \\
\hline 18 & $\mathbf{k}$ & $\mathrm{CO}_{2} \mathrm{Me}$ & $4-\mathrm{MeOC}_{6} \mathrm{H}_{4} \mathrm{CH}_{2}$ & $5 k$ & 83 \\
\hline 19 & I & $\mathrm{CO}_{2} \mathrm{Me}$ & $4-\mathrm{ClC}_{6} \mathrm{H}_{4}$ & $5 I$ & 81 \\
\hline 20 & m & $\mathrm{CO}_{2} \mathrm{Me}$ & $4-\mathrm{MeOC}_{6} \mathrm{H}_{4}$ & $5 m$ & 81 \\
\hline
\end{tabular}


Table 3: Screening of the reaction conditions for organic base-catalyzed malonic acid monophenyl ester (1a) addition to 1-methyl-4-trifluoromethylpyrimidin-2(1H)-one $(\mathbf{2 a})$.

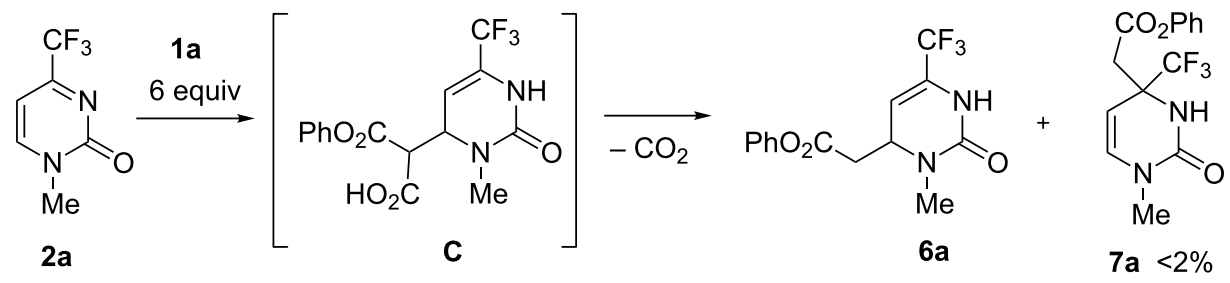

\begin{tabular}{lllllll}
\hline entry & solvent & base & temp. $\left({ }^{\circ} \mathrm{C}\right)$ & time $(\mathrm{h})$ & conv. & yield 6a $(\%)^{\mathrm{a}}$ \\
\hline 1 & toluene & TEA & 80 & 4 & 98 & 81 \\
2 & toluene & DIEA & 80 & 4 & 96 & 77 \\
3 & toluene & DBU & 80 & 4 & 10 & - \\
4 & toluene & quinine & 80 & 4 & 92 & $68^{\mathrm{b}}$ \\
5 & toluene & QT & 80 & 4 & 78 & $55^{\mathrm{b}}$ \\
6 & $\mathrm{CH}_{2} \mathrm{Cl}_{2}$ & TEA & 40 & 8 & 94 & 75 \\
7 & THF & TEA & 66 & 8 & 90 & 74 \\
8 & dioxane & TEA & 80 & 4 & 91 & 80 \\
9 & DMSO & TEA & 80 & 4 & 93 & 81 \\
\hline
\end{tabular}

aThe regioisomeric product 7 a was formed in a negligible amount in all cases; ${ }^{\text {b }}$ Racemic product.

the presence of a stoichiometric amount of TEA or DIEA (Table 3, entries 1 and 2). Under these conditions the reaction provided the Michael-type adduct, phenyl 2-(3-methyl-2-oxo-6trifluoromethyl-1,2,3,4-tetrahydropyrimidin-4-yl)acetate (6a). The presence of DBU caused substantial decarboxylation of starting reagent 1 a (Table 3 , entry 3 ). This unwanted process necessitated using of up to 6 equivalents of $1 \mathbf{a}$ to reach a reasonable conversion with TEA as catalyst. Quinine and QT were again found to be ineffective to promote the enantioselective reaction (Table 3, entries 4 and 5). In contrast to the reaction with malonic acid under similar conditions, just trace amounts of regioisomeric Mannich-type adduct 7a were detected. Presumably, in this case, the kinetically controlled Michael-type intermediate $\mathbf{C}$ is even far more prone to decarboxylation than the dicarboxylate intermediate $\mathbf{A}$ (Table 1) and hence, the reaction is sufficiently regioselective irrespective of the solvent polarity (Table 3, entries 1, and 6-9). Performing the reaction in toluene in the presence of TEA ( 1 equiv) at $80{ }^{\circ} \mathrm{C}$ for 4 hours gave the best result in terms of regioselectivity and yield of $\mathbf{6 a}$ (Table 3, entry 1), virtually the only product formed in all the solvents used here (as evidenced by ${ }^{19} \mathrm{~F}$ NMR monitoring).

The addition of malonic acid monophenyl ester (1a) to substituted pyrimidones $\mathbf{2} \mathbf{b}-\mathbf{e}$ carried out in the presence of TEA in toluene for $8 \mathrm{~h}$ has shown that a substituent at position 1 of the pyrimidine ring can significantly influence the progress of the reaction (Table 4). Thus, N1-alkyl-substituted compounds $\mathbf{2 b - e}$ exhibited a lower reactivity compared to $\mathbf{2 a}$ and the corresponding products $\mathbf{6 b}-\mathbf{e}$ were not isolated due to low conversion and regioselectivity (Table 4, entries 1-4). These are likely caused by the enhanced steric hindrance around the neighboring electrophilic position 6 and also the lowered electrophilicity of the reaction center. Consequently, the nucleophilic attack on the $\mathrm{C}=\mathrm{N}$ double bond becomes equally probable thus leading to the loss of regioselectivity. Fortunately, allyl and various benzyl or phenyl substituents in derivatives $\mathbf{2} \mathbf{f}-\mathbf{m}$ allowed the regioselective synthesis of products $\mathbf{6 f}-\mathbf{m}$ in high yields (Table 4 , entries $5-12$ ). We found that the ester group at position 5 significantly increases the electrophilicity of the endocyclic $\mathrm{C}=\mathrm{C}$ double bond giving rise to faster addition of $\mathbf{1 a}$ and higher regioselectivity of products $\mathbf{6 j}-\mathbf{m}$ (Table 4 , entries 9-12). Like $N 3$-unsubstituted compounds 5n,o, their phenyl ester analogues 6n,o were obtained by the cleavage of the N3-PMB substituent on short heating in TFA (see Table 4). It has been shown that acids $\mathbf{4 a}, \mathbf{f}-\mathbf{m}$ can be synthesized alternatively by alkaline hydrolysis of esters $\mathbf{6 a}, \mathbf{f}-\mathbf{m}$ (see Supporting Information File 1 for full experimental data). The ester group at position 5 remained intact during the hydrolysis.

Malonic acid monothioesters are known to be more reactive C-nucleophiles than the corresponding esters [41]. Therefore, we studied the decarboxylative addition of compound $\mathbf{1 b}$ as representative example to substrates $\mathbf{2 a - m}$ (Table 5). They were found to furnish Michael-type addition products $\mathbf{8 a}-\mathbf{m}$ on 
Table 4: Regioselective decarboxylative addition of malonic acid monophenyl ester (1a) to 4-trifluoromethylpyrimidin-2(1H)-ones $\mathbf{2 b - m}$ and preparation of N3-unsubstituted compounds $6 \mathbf{n}, \mathbf{0}$

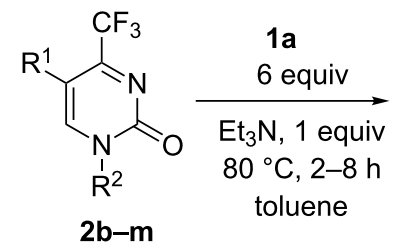

$2 \mathbf{b}-\mathbf{m}$<smiles>[R]C1=C(C(F)(F)F)NC(=O)N([R])C1CC(=O)Oc1ccccc1</smiles>

6f-m 70-80\%

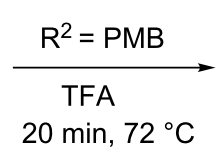

$20 \min , 72^{\circ} \mathrm{C}$<smiles>[OH2+]O[PbH2]</smiles><smiles>[R]C1=C(C(F)(F)F)NC(=O)NC1CC</smiles>

6n $\left(R^{1}=H\right), 72 \%$

6 o $\left(\mathrm{R}^{1}=\mathrm{CO}_{2} \mathrm{Me}\right), 68 \%$

\begin{tabular}{|c|c|c|c|c|c|c|}
\hline entry & comp. 2, 6 & $\mathrm{R}^{1}$ & $\mathrm{R}^{2}$ & time $(h)$ & conv. & yield $6(\%)$ \\
\hline 1 & b & $\mathrm{H}$ & Et & 8 & 50 & - \\
\hline 2 & c & $\mathrm{H}$ & $n-\mathrm{Bu}$ & 8 & 55 & - \\
\hline 3 & d & $\mathrm{H}$ & $\mathrm{Me}_{2} \mathrm{CHCH}_{2}$ & 8 & 49 & - \\
\hline 4 & e & $\mathrm{H}$ & $\mathrm{MeOCH}_{2} \mathrm{CH}_{2}$ & 8 & 44 & - \\
\hline 5 & $f$ & $\mathrm{H}$ & $\mathrm{CH}_{2}=\mathrm{CHCH}_{2}$ & 4 & 97 & 75 \\
\hline 6 & $\mathbf{g}$ & $\mathrm{H}$ & $\mathrm{Bn}$ & 4 & 99 & 70 \\
\hline 7 & $\mathbf{h}$ & $\mathrm{H}$ & $4-\mathrm{FC}_{6} \mathrm{H}_{4} \mathrm{CH}_{2}$ & 4 & 99 & 74 \\
\hline 8 & $\mathbf{i}$ & $\mathrm{H}$ & 4- $\mathrm{MeOC}_{6} \mathrm{H}_{4} \mathrm{CH}_{2}$ & 4 & 98 & 69 \\
\hline 9 & $\mathbf{j}$ & $\mathrm{CO}_{2} \mathrm{Me}$ & $4-\mathrm{FC}_{6} \mathrm{H}_{4} \mathrm{CH}_{2}$ & 2 & 99 & 80 \\
\hline 10 & k & $\mathrm{CO}_{2} \mathrm{Me}$ & 4- $\mathrm{MeOC}_{6} \mathrm{H}_{4} \mathrm{CH}_{2}$ & 2 & 97 & 71 \\
\hline 11 & 1 & $\mathrm{CO}_{2} \mathrm{Me}$ & $4-\mathrm{ClC}_{6} \mathrm{H}_{4}$ & 2 & 98 & 73 \\
\hline 12 & m & $\mathrm{CO}_{2} \mathrm{Me}$ & $4-\mathrm{MeOC}_{6} \mathrm{H}_{4}$ & 2 & 99 & 75 \\
\hline
\end{tabular}

Table 5: Regioselective decarboxylative addition of malonic acid mono-4-methoxyphenyl thioester (1b) to 4-trifluoromethylpyrimidin-2(1H)-ones $2 a-m$.<smiles>[R]c1cn([R])c(=O)nc1C(F)(F)F</smiles>

$2 a-m$

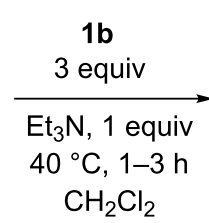

$\mathrm{CH}_{2} \mathrm{Cl}_{2}$<smiles>[R]C1=C(C(F)(F)F)NC(=O)N([R2])C1CC(=O)Sc1ccc(OC)cc1</smiles>

$8 \mathbf{a}-\mathbf{m}$

\begin{tabular}{|c|c|c|c|c|c|}
\hline entry & comp. 2, 8 & $\mathrm{R}^{1}$ & $\mathrm{R}^{2}$ & time $(\mathrm{h})$ & yield $8(\%)$ \\
\hline 1 & $\mathbf{a}$ & $\mathrm{H}$ & $\mathrm{Me}$ & 3 & 83 \\
\hline 2 & b & $\mathrm{H}$ & Et & 3 & 71 \\
\hline 3 & c & $\mathrm{H}$ & $n-\mathrm{Bu}$ & 3 & 77 \\
\hline 4 & d & $\mathrm{H}$ & $\mathrm{Me}_{2} \mathrm{CHCH}_{2}$ & 3 & 77 \\
\hline 5 & e & $\mathrm{H}$ & $\mathrm{MeOCH}_{2} \mathrm{CH}_{2}$ & 3 & 75 \\
\hline 6 & f & $\mathrm{H}$ & $\mathrm{CH}_{2}=\mathrm{CHCH}_{2}$ & 3 & 73 \\
\hline 7 & $\mathbf{g}$ & $\mathrm{H}$ & $\mathrm{Bn}$ & 3 & 74 \\
\hline 8 & h & $\mathrm{H}$ & $4-\mathrm{FC}_{6} \mathrm{H}_{4} \mathrm{CH}_{2}$ & 3 & 71 \\
\hline 9 & $\mathbf{i}$ & $\mathrm{H}$ & 4- $\mathrm{MeOC}_{6} \mathrm{H}_{4} \mathrm{CH}_{2}$ & 3 & 70 \\
\hline 10 & $\mathbf{j}$ & $\mathrm{CO}_{2} \mathrm{Me}$ & $4-\mathrm{FC}_{6} \mathrm{H}_{4} \mathrm{CH}_{2}$ & 1 & 77 \\
\hline 11 & $\mathbf{k}$ & $\mathrm{CO}_{2} \mathrm{Me}$ & 4- $\mathrm{MeOC}_{6} \mathrm{H}_{4} \mathrm{CH}_{2}$ & 1 & 75 \\
\hline 12 & I & $\mathrm{CO}_{2} \mathrm{Me}$ & $4-\mathrm{ClC}_{6} \mathrm{H}_{4}$ & 1 & 81 \\
\hline 13 & m & $\mathrm{CO}_{2} \mathrm{Me}$ & 4- $\mathrm{MeOC}_{6} \mathrm{H}_{4}$ & 1 & 72 \\
\hline
\end{tabular}

heating in $\mathrm{CH}_{2} \mathrm{Cl}_{2}$ at $40{ }^{\circ} \mathrm{C}$ in excellent yields. Moreover, Satisfactory conversion and regioselectivity were achieved even 3 equivalents excess of $\mathbf{1 b}$ was sufficient for the reaction to be with substrates $\mathbf{2} \mathbf{b}-\mathbf{e}$ bearing ethyl, $n$-butyl, isobutyl and completed within 1-3 hours.

2-methoxyethyl substituents which demonstrated low reactivity 
in the addition reaction with ester analogue 1a. It can thus be inferred that the substituents $\mathrm{R}^{1}$ and $\mathrm{R}^{2}$ have almost no impact on the outcome of the decarboxylative addition provided a highly reactive nucleophilic component such as malonic acid monothioester $\mathbf{1 b}$ is used.

Importantly, representative compounds $\mathbf{6 a}, \mathbf{j}$ and $\mathbf{8 f}$ readily reacted with benzylamine thus showing the possibility of esters $\mathbf{6}$ and thioesters 8 to be convenient amine acylating agents [32] and, hence, building blocks for direct preparation of the amide derivatives (see Supporting Information File 1 for examples of the corresponding amide syntheses).

In a next set of experiments, the endocyclic $\mathrm{C}=\mathrm{C}$ double bond of the decarboxylative adducts 4-6 were hydrogenated to prepare compounds with a saturated 3,4,5,6-tetrahydropyrimidin-2 $(1 H)$-one ring functionalized with an acetic acid moiety and a trifluoromethyl group. Thus, the acids $4 \mathbf{4 a}, \mathbf{g}, \mathbf{i}$ quantitatively yielded reduced products $\mathbf{9 a - c}$ under mild catalytic conditions (when reacted with hydrogen at atmospheric pressure and room temperature for 3 hours in the presence of $10 \% \mathrm{Pd} / \mathrm{C}$ catalyst) as shown in Scheme 1. The simplest acetic acid derivative 9d was synthesized from $9 \mathbf{c}$ in a good yield by using the general procedure for N1-PMB cleavage. Likewise, regioisomeric acids 5a,g,i and their phenyl esters $\mathbf{6 a}, \mathbf{g}, \mathbf{i}$ were reduced to the respective saturated compounds $10 a-c$ and $11 \mathbf{a}-\mathbf{c}$ In this case a high hydrogenation cis-stereoselectivity is provided when the $\mathrm{Pd} / \mathrm{C}$ catalyst loading is smaller than 20 weight $\%$ (otherwise the reaction proceeds too fast leading to diastereomeric mixtures with a cis- to trans-ratio of up to $3: 1)$.
The relative cis-configuration of the $\mathrm{CF}_{3}$ and $\mathrm{CH}_{2} \mathrm{COOPh}$ substituents in the prepared phenyl (2-oxo-6-trifluoromethylhexahydropyrimidin-4-yl)acetates $\mathbf{1 1 a}-\mathbf{c}$ was unambiguously corroborated by a single-crystal X-ray diffraction study of compound 11b (Figure 2, see Supporting Information File 1 for full structure description and experimental data). The configurationpreserving conversion of ester $\mathbf{1 1 b}$ into acid $\mathbf{1 0 b}$ by simple alkaline hydrolysis has also confirmed the cis-geometry for acids $10 a-c$ obtained by direct hydrogenation of compounds 5a,g,i (see Supporting Information File 1). N3-Unsubstituted compounds 10d and 11d with the preserved cis-configuration of the substituents were readily prepared from the corresponding $N 3-\mathrm{PMB}$ derivatives $\mathbf{1 0 c}$ and $11 \mathrm{c}$ by using the general procedure for N1(3)-PMB cleavage (see Scheme 1).

\section{Conclusion}

In conclusion, it has been demonstrated that the efficient and highly regioselective organocatalytic decarboxylative addition of malonic acid or its derivatives to 4-trifluoromethylpyrimidin$2(1 H)$-ones 2 is perfectly feasible with a precise control of the reaction conditions. A remarkable solvent effect has been observed which governs the ratio of the resulting regioisomeric decarboxylated adducts $\mathbf{4}$ and $\mathbf{5}$ and allows their preparative selective isolation. This effect may well be attributed to a twostep mechanism of the decarboxylative nucleophilic addition which is characterized by a faster decarboxylation of kinetically-controlled Michael-type intermediates in high-polar solvents.

Though malonic monoester 1a appears to be similar to malonic acid in reactivity towards compounds $\mathbf{2}$, it produces exclusively

( 


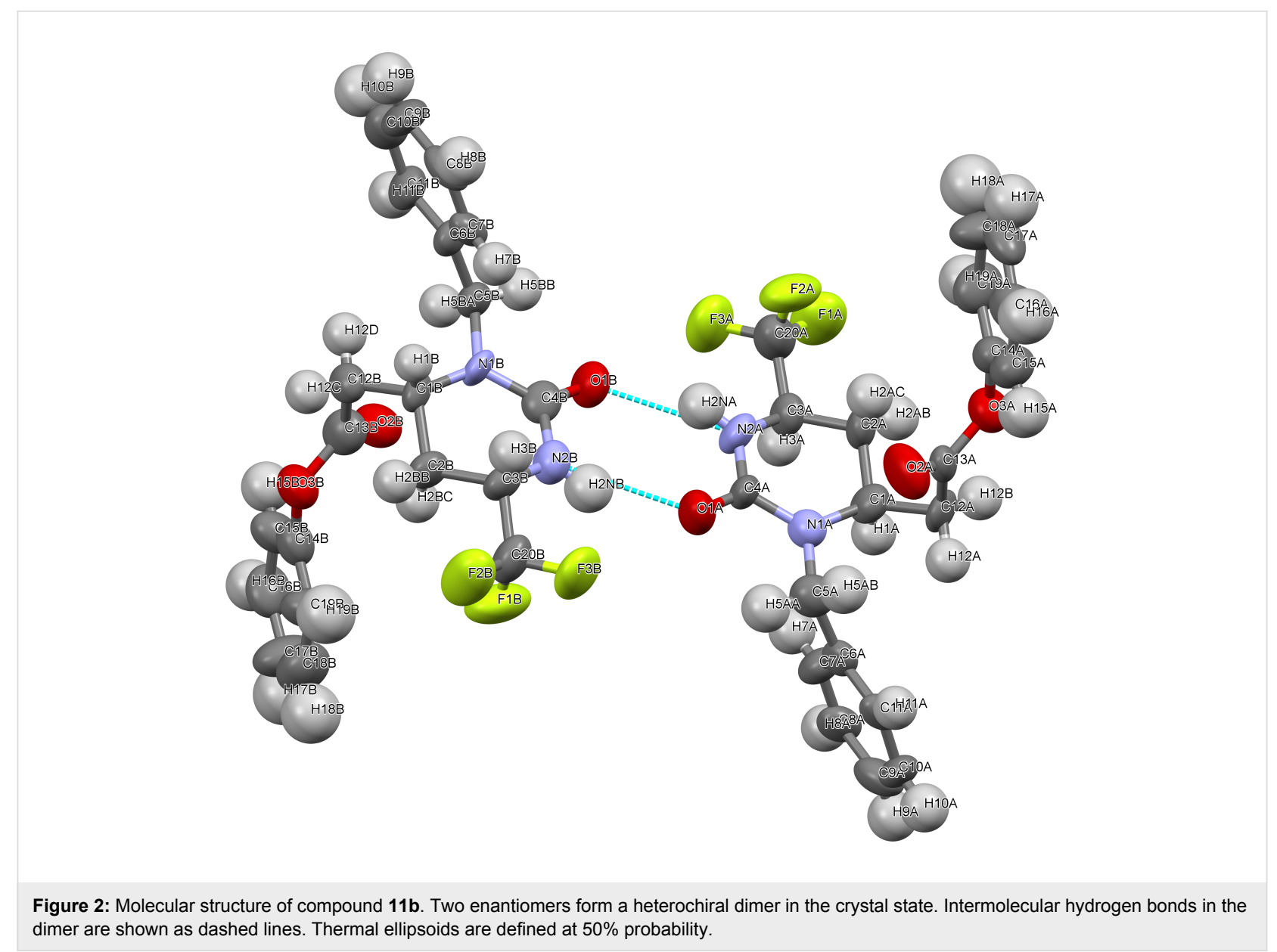

Michael-type adducts 6 regardless of the reaction conditions used. Likewise, the more reactive malonic mono thioester $\mathbf{1 b}$, when reacted with a broader scope of substrates $\mathbf{2}$ under milder conditions, gives rise only to analogous Michael-type products 8. In general, the reactivity of substrates 2 can be increased by introduction of the ester functionality at position 5 as well as allyl, various benzyl or phenyl substituents at position 1 of the pyrimidine core. Notably, esters 6 and thioesters 8 are remarkable for their potential application as smooth amine acylating agents.

It has been shown that the 3,4-dihydropyrimidin-2(1H)-one ring in both Mannich- and Michael-type products $\mathbf{4}$ and 5, $\mathbf{6}$ can be readily hydrogenated under mild catalytic conditions to furnish saturated compounds 9 and 10, 11, respectively. Products $\mathbf{1 0}$ and $\mathbf{1 1}$ featuring two stereogenic centers were obtained only as cis-isomers.

$N 1$ (3)-Unsubstituted products $4 \mathbf{j}, \mathbf{5 n}, \mathbf{0}, \mathbf{6 n}, \mathbf{o}$, and 9-11d, unavailable by direct decarboxylative addition, are readily accessible by TFA-mediated cleavage of the corresponding N1(3)-PMB substituted precursors.

\section{Supporting Information}

\section{Supporting Information File 1}

Experimental procedures, characterization data and X-ray structure determination for compound $\mathbf{1 1 b}$.

[http://www.beilstein-journals.org/bjoc/content/ supplementary/1860-5397-13-259-S1.pdf]

\section{Supporting Information File 2}

Copies of the ${ }^{1} \mathrm{H},{ }^{13} \mathrm{C}$, and ${ }^{19} \mathrm{~F}$ NMR spectra.

[http://www.beilstein-journals.org/bjoc/content/ supplementary/1860-5397-13-259-S2.pdf]

\section{ORCID ${ }^{\circledR}$ iDs}

Svitlana V. Shishkina - https://orcid.org/0000-0002-3946-1061 Volodymyr A. Sukach - https://orcid.org/0000-0002-2891-343X

\section{References}

1. Liang, Y.; Feng, D.; Wu, Y.; Tsai, S.-T.; Li, G.; Ray, C.; Yu, L. J. Am. Chem. Soc. 2009, 131, 7792-7799. doi:10.1021/ja901545q 
2. Son, H. J.; Wang, W.; Xu, T.; Liang, Y.; Wu, Y.; Li, G.; Yu, L. J. Am. Chem. Soc. 2011, 133, 1885-1894. doi:10.1021/ja108601g

3. Stuart, A. C.; Tumbleston, J. R.; Zhou, H.; Li, W.; Liu, S.; Ade, H.; You, W. J. Am. Chem. Soc. 2013, 135, 1806-1815. doi:10.1021/ja309289u

4. Brooks, A. F.; Topczewski, J. J.; Ichiishi, N.; Sanford, M. S.; Scott, P. J. H. Chem. Sci. 2014, 5, 4545-4553. doi:10.1039/C4SC02099E

5. Jeschke, P. ChemBioChem 2004, 5, 570-589. doi:10.1002/cbic. 200300833

6. Jeschke, P. Pest Manage. Sci. 2010, 66, 10-27. doi:10.1002/ps.1829

7. Chen, H.; Viel, S.; Ziarelli, F.; Peng, L. Chem. Soc. Rev. 2013, 42, 7971-7982. doi:10.1039/c3cs60129c

8. Marsh, E. N. G.; Suzuki, Y. ACS Chem. Biol. 2014, 9, 1242-1250. doi:10.1021/cb500111u

9. Wang, J.; Sánchez-Roselló, M.; Aceña, J. L.; del Pozo, C.; Sorochinsky, A. E.; Fustero, S.; Soloshonok, V. A.; Liu, H. Chem. Rev. 2014, 114, 2432-2506. doi:10.1021/cr4002879

10. Zhou, Y.; Wang, J.; Gu, Z.; Wang, S.; Zhu, W.; Aceña, J. L.; Soloshonok, V. A.; Izawa, K.; Liu, H. Chem. Rev. 2016, 116, 422-518. doi:10.1021/acs.chemrev.5b00392

11. Liang, T.; Neumann, C. N.; Ritter, T. Angew. Chem., Int. Ed. 2013, 52, 8214-8264. doi:10.1002/anie.201206566

12. Yerien, D. E.; Bonesi, S.; Postigo, A. Org. Biomol. Chem. 2016, 14, 8398-8427. doi:10.1039/c6ob00764c

13. Yang, X.; Wu, T.; Phipps, R. J.; Toste, F. D. Chem. Rev. 2015, 115, 826-870. doi:10.1021/cr500277b

14. Bizet, V.; Besset, T.; Ma, J.-A.; Cahard, D. Curr. Top. Med. Chem. 2014, 14, 901-940. doi:10.2174/1568026614666140202205531

15. Percy, J. M. Building Block Approaches to Aliphatic Organofluorine Compounds. In Organofluorine Chemistry, Techniques and Synthons; Chambers, R. D., Ed.; Topics in Current Chemistry, Vol. 193; Springer: Berlin, 1998; pp 131-195. doi:10.1007/3-540-69197-9_4

16. Ren, X.; Wan, W.; Jiang, H.; Hao, J. Mini-Rev. Org. Chem. 2007, 4, 330-337. doi:10.2174/157019307782411662

17. Zhu, S. Z.; Wang, Y. L.; Peng, W. M.; Song, L. P.; Jin, G. F. Curr. Org. Chem. 2002, 6, 1057-1096. doi:10.2174/1385272023373635

18. Wu, Y.; Hu, L.; Li, Z.; Deng, L. Nature 2015, 523, 445-450. doi:10.1038/nature14617

19. Kutovaya, I. V.; Shmatova, O. I.; Tkachuk, V. M.; Melnichenko, N. V.; Vovk, M. V.; Nenajdenko, V. G. Eur. J. Org. Chem. 2015, 6749-6761. doi:10.1002/ejoc.201500898

20. Morisaki, K.; Sawa, M.; Yonesaki, R.; Morimoto, H.; Mashima, K.; Ohshima, T. J. Am. Chem. Soc. 2016, 138, 6194-6203. doi:10.1021/jacs.6b01590

21. Sanz-Vidal, Á.; Miró, J.; Sánchez-Roselló, M.; del Pozo, C.; Fustero, S. J. Org. Chem. 2016, 81, 6515-6524. doi:10.1021/acs.joc.6b01139

22. Miró, J.; Sánchez-Roselló, M.; González, J.; del Pozo, C.; Fustero, S. Chem. - Eur. J. 2015, 21, 5459-5466. doi:10.1002/chem.201406224

23. Han, X.; Wu, H.; Wang, W.; Dong, C.; Tien, P.; Wu, S.; Zhou, H.-B. Org. Biomol. Chem. 2014, 12, 8308-8317. doi:10.1039/C4OB01333F

24. Lou, H.; Wang, Y.; Jin, E.; Lin, X. J. Org. Chem. 2016, 81, 2019-2026. doi:10.1021/acs.joc.5b02848

25. Zhou, B.; Jiang, C.; Rao Gandi, V.; Lu, Y.; Hayashi, T. Chem. - Eur. J. 2016, 22, 13068-13071. doi:10.1002/chem.201603105

26. Zhou, D.; Huang, Z.; Yu, X.; Wang, Y.; Li, J.; Wang, W.; Xie, H. Org. Lett. 2015, 17, 5554-5557. doi:10.1021/acs.orglett.5b02668

27. Yang, L.-J.; Li, S.; Wang, S.; Nie, J.; Ma, J.-A. J. Org. Chem. 2014, 79, 3547-3557. doi:10.1021/jo500356t
28. Yuan, H.-N.; Li, S.; Nie, J.; Zheng, Y.; Ma, J.-A. Chem. - Eur. J. 2013, 19, 15856-15860. doi:10.1002/chem.201303307

29. Shmatova, O. I.; Shevchenko, N. E.; Balenkova, E. S.; Röschenthaler, G.-V.; Nenajdenko, V. G. Eur. J. Org. Chem. 2013, 15, 3049-3058. doi:10.1002/ejoc.201201725

30. Ricci, A.; Pettersen, D.; Bernardi, L.; Fini, F.; Fochi, M.; Herrera, R. P.; Sgarzani, V. Adv. Synth. Catal. 2007, 349, 1037-1040. doi:10.1002/adsc.200600536

31. Li, X.-J.; Xiong, H.-Y.; Hua, M.-Q.; Nie, J.; Zheng, Y.; Ma, J.-A. Tetrahedron Lett. 2012, 53, 2117-2120. doi:10.1016/j.tetlet.2012.02.053

32. Bae, H. Y.; Sim, J. H.; Lee, J.-W.; List, B.; Song, C. E. Angew. Chem., Int. Ed. 2013, 52, 12143-12147. doi:10.1002/anie.201306297

33. Jia, C.-M.; Zhang, H.-X.; Nie, J.; Ma, J.-A. J. Org. Chem. 2016, 81, 8561-8569. doi:10.1021/acs.joc.6b01750

34. Saadi, J.; Wennemers, H. Nat. Chem. 2016, 8, 276-280. doi:10.1038/nchem.2437

35. Bernardi, L.; Fochi, M.; Franchini, M. C.; Ricci, A. Org. Biomol. Chem. 2012, 10, 2911-2922. doi:10.1039/C2OB07037E

36. Nakamura, S. Org. Biomol. Chem. 2014, 12, 394-405. doi:10.1039/C3OB42161A

37. Sukach, V. A.; Tkachuk, V. M.; Shoba, V. M.; Pirozhenko, V. V.; Rusanov, E. B.; Chekotilo, A. A.; Röschenthaler, G.-V.; Vovk, M. V. Eur. J. Org. Chem. 2014, 1452-1460. doi:10.1002/ejoc.201301542

38. Tkachuk, V. M.; Sukach, V. A.; Kovalchuk, K. V.; Vovk, M. V.; Nenajdenko, V. G. Org. Biomol. Chem. 2015, 13, 1420-1428. doi:10.1039/C4OB02233E

39. Sukach, V. A.; Resetnic, A. A.; Tkachuk, V. M.; Lin, Z.; Kortz, U.; Vovk, M. V.; Röschenthaler, G.-V. Eur. J. Org. Chem. 2015, 1290-1301. doi:10.1002/ejoc.201403495

40. Midyana, G. G.; Makitra, R. G.; Pal'chikova, E. Y. Russ. J. Gen. Chem. 2010, 80, 944-947. doi:10.1134/S1070363210050142

41. Bew, S. P.; Stephenson, G. R.; Rouden, J.; Godemert, J.; Seylani, H.; Martinez-Lozano, L. A. Chem. - Eur. J. 2017, 23, 4557-4569. doi:10.1002/chem.201605148

\section{License and Terms}

This is an Open Access article under the terms of the Creative Commons Attribution License (http://creativecommons.org/licenses/by/4.0), which permits unrestricted use, distribution, and reproduction in any medium, provided the original work is properly cited.

The license is subject to the Beilstein Journal of Organic Chemistry terms and conditions: (http://www.beilstein-journals.org/bjoc)

The definitive version of this article is the electronic one which can be found at: doi: $10.3762 /$ bjoc. 13.259 